\title{
Effect of nutritional status on Rohingya under-five children in Bangladesh
}

\author{
Md. Hasib ${ }^{1}$, Md. Nazmul Hassan ${ }^{2}$, Mehedi Hasan ${ }^{3}$, Md. Shafiqul Islam Khan ${ }^{4}$ \\ ${ }^{1,2,3}$ Department of Environmental Sanitation, Patuakhali Science and Technology University, Bangladesh \\ ${ }^{4}$ Department of Food Microbiology, Patuakhali Science and Technology University, Bangladesh
}

\section{Article Info \\ Article history: \\ Received Jun 26, 2020 \\ Revised Aug 30, 2020 \\ Accepted Sep 11, 2020}

\section{Keywords:}

Effect

Nutritional status

Rohingya children

Under-five children

\begin{abstract}
The extent of nutritional status affecting Rohingya refugee under-five children has become a major health issues in Bangladesh. This study aimed to investigate the nutritional status and its effect on under-five Rohingya children in comparison with the areas of Bangladesh. A cross-sectional study of 300 under-five children were conducted by structured questionnaire from Rohingya camp (100), Cox's Bazar (100) and Dumki (100) applying simple random method. Anthropometric indices (weight, height, mid-upper arm circumference (MUAC)) were measured in children aged 6-59 months. Indices were reported in z-scores and compared with WHO 2005 reference population. Data were analyzed by WHO Anthro-Plus Software and SPSS. About $41 \%$ Rohingya, $43 \%$ surrounding areas, and $46 \%$ Dumki were stunting in height-for-age z-score (HAZ) score respectively. Near about $13 \%, 11 \%$ and $4 \%$ were wasting in weight-for-height $\mathrm{z}$-score (WHZ) score and $18 \%, 15 \%$ and $10 \%$ were underweight in weight for age Z-score (WAZ) score respectively. Food groups, Disease, worm infestation among 3 study areas were statistically significant $(\mathrm{P}<.05)$. Moreover, handwashing practice, vitamin-A consumption and worm infestation effects among diseases were statistically significant. In this study population, there was high prevalence of malnutrition among Rohingya children, especially wasting and underweight compared to other areas. Prevention of malnutrition plays an important role for having a healthy society of Rohingya Refugees.
\end{abstract}

This is an open access article under the CC BY-SA license.

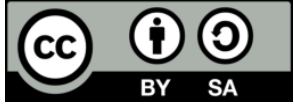

\section{Corresponding Author:}

Md. Hasib,

Department of Environmental Sanitation,

Patuakhali Science and Technology University,

Bangladesh.

Email: mohammadhasib39@gmail.com

\section{INTRODUCTION}

Rohingya Refugee children represent an expanding vulnerable population in Bangladesh who are at high risk for health and nutritional disparities. The number of refugees in the world started to increase with 2014 estimating 14.4 million individuals meeting the united nations high commission for refugees (UNHCR) definition which represents the highest numbers of refugees reported since 1995 [1]. Whereas, in Bangladesh Rohingya refugee camps accommodating approximately 836000 refugees among which 33956 are under-five children who are mostly vulnerable for their health condition [2,3]. Thus, under-five children are more vulnerable and tends to fall in the high risk groups occurring death during the first five years of life [4]. Therefore, child under nutrition is a big and urgent deal for all and if we neglects child under nutrition it will affect both health and development [5]. 
The Rohingya people of Myanmar had been subjected to government-sponsored discrimination, detention, violence, and torture, causing several waves of a mass exodus to Bangladesh and took place in refugee camps in Cox's Bazar where they are devoid of basic needs such as education, health care, employment and freedom of movement $[6,7]$. The prevalence of malnutrition of Rohingya Refugee underfive children was above the World Health Organization's emergency threshold level [6, 8]. Therefore, under nutrition increases a child's risk of morbidity and mortality associated with infectious disease, and poor cognitive and developmental outcomes [9]. On the other hand poor nutrition status is the leading cause of infectious diseases [9, 10]. So, prevention of diseases or early detection of malnutrition will ultimately improve the nutritional status of under-five children [11].

In addition, assessment of nutritional status and treatments of the Rohingya's children has become a controversial issues for Bangladesh because they are competing with the local community for scant resources as well as they are blamed for growing tensions in Bangladesh [12-14]. Despite of the controversy Bangladesh has responded by providing the Rohingya refugees access to UNHCR services while continuing not to deny them [15]. Although, Rohingya crisis scenario in Bangladesh is going to take a monster shape but the different study of Rohingya issues extracted the prevalence of wasting, stunting, underweight and overweight condition of the Rohingya Refugee under-five children [16-18]. Published reports on Rohingya refugee under-five children are lacking in finding the effect of nutritional status and also there are no prior studies ever like ours carried out in Bangladesh. Therefore, this study was designed to investigate the effect of nutritional status on 0-5 years Rohingya children as well as the comparison of the nutritional status with other areas of Bangladesh (surroundings of Cox's Bazar and Dumki, Patuakhali).

\section{RESEARCH METHOD}

\subsection{Study setting}

Participants from this study were selected from Rohingya Refugee Camp of Kutupalong (Cox's Bazar), the surrounding area of Cox's Bazar where the Bangladeshi families reside and Dumki, Patuakhali during July-September, 2019 where under-five children of different socioeconomic classes (lower and upper) were present. Therefore, the researcher considered this area for data collection.

\subsection{Study design}

This was a cross-sectional study of 300 respondents which was conducted by a structured questionnaire in Rohingya refugee camp, surrounding area of Cox's Bazar and Dumki, Patuakhali by the process of simple random sampling. Data collected of age groups 0-5 years of permanent residence in and around refugee camp along with both diseased and non-diseased children excluding the temporary residence. Data includes all the possible outcomes obtained from the questionnaire by direct interviewing of respondents that was the family members of the children. Anthropometric measurements viz. height and weight were measured as per the guidelines suggested by WHO. Height was measured by using a height measuring tape nearest to $0.1 \mathrm{~cm}$. A portable personal weighing scale was used to measure the weight in kilograms nearest to $0.1 \mathrm{~kg}$, with ordinary casual clothing and without shoes. Food groups charts (foods containing Carbohydrates, protein, fats and oils, fruits and vegetables, dairy products) to see the dietary pattern of the children.

\subsection{Questionnaire}

The structured questionnaire includes anthropometric measurement (height and weight), MUAC tape measurement, worm infestation, disease condition (if the children were suffering from diseases or not), hand washing practice, Vitamin A consumption and food groups taken 4/4+ respectively. The worm infestation was measured by intake of tablets during past 14 days or not. The questionnaire includes proper hand washing practice (done/not done) was also documented in our questionnaire. On the other hand immunization with vitamin A capsule recently was also documented because vitamin A consumption supports rapid bone growth and bone developments as well as the vision. Moreover, diseased condition of the participating children were also documented as disease (present/absent).

\subsection{Data collection}

A research assistant was recruited and trained up for the fieldwork of the study who was responsible for only sample selection, collection of data by reviewing the questionnaire through teamwork with the researcher. Anthropometric measurement was taken by height and weight machine. MUAC tape measurement of the children was taken by the MUAC tape. Collection of the data was done randomly where our interviewers interviewed face to face with the family member's father/mother/other family members who were adopting the children. 


\subsection{Ethical approval}

All study procedures were carried out following the guidelines of the Helsinki Declaration, 1975. Written ethical approval was obtained from the Research Ethical Committee, Department of Environmental Sanitation, Patuakhali Science and Technology University (Ref. ENS/REC/2019/02). The local stakeholders were informed previously so that the respondents co-operates with us. The respondents were also assured about the confidentiality and anonymity of the data.

\subsection{Statistical analysis}

Collected data were scrutinized and summarized for the purpose of tabulation using Anthro software of WHO version 3.2.2 and statistical package for social sciences (SPSS) version 20. Anthropometric indices (weight, height, mid-upper arm circumference) were measured in children aged 6-59 months following standard procedures. Indices were reported in z-scores and compared with WHO 2005 reference population where height for age Z-score (HAZ) showed stunting percentage, weight for age Z-score (WAZ) showed underweight, weight for height Z-score (WHZ) showed wasting and overweight among the participating children. Hand washing practice, vitamin A consumption, worm infestation, disease condition and food groups were taken from the children. The effect of nutritional status was analyzed by using One Way ANOVA and Independent t-test.

\section{RESULTS}

The Table 1 provides the salient of our study which indicates of weight for height $\mathrm{Z}$ score (WHZ), height for age Z score (HAZ) and weight for age Z score (WAZ) of three different study area. About 41\% Rohingya, 43\% surrounding areas, and $46 \%$ Dumki were stunting in HAZ score respectively. Near about $13 \%, 11 \%$ and $4 \%$ were wasting in WHZ score and 18\%, $15 \%$ and $10 \%$ were underweight in WAZ score respectively. Vitamin A intake over the study area were $36 \%, 43 \%$ and $62 \%$ respectively along with disease $15 \%, 8 \%$ and $4 \%$ respectively. Moreover, hand washing and 4/4+ food groups taken were $47 \%, 58 \%, 75 \%$ and $65 \%, 49 \%, 42 \%$ respectively.

Table 1. Comparison of nutritional status among Rohingya children and Bangladesh children

\begin{tabular}{|c|c|c|c|}
\hline Respondents information & Rohingya children \% & $\begin{array}{l}\text { Bangladesh children \% } \\
\text { surrounding of Cox's Bazar }\end{array}$ & $\begin{array}{l}\text { Bangladesh children \% } \\
\text { Dumki, Patuakhali }\end{array}$ \\
\hline \multicolumn{4}{|c|}{ 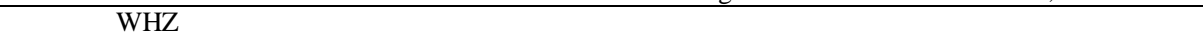 } \\
\hline Wasting & 13 & 11 & 4 \\
\hline Moderate Wasting & 8 & 9 & 4 \\
\hline Severe Wasting & 5 & 2 & 0 \\
\hline Normal & 84 & 85 & 89 \\
\hline Overweight (WHZ> 2) & 3 & 04 & 7 \\
\hline \multicolumn{4}{|l|}{ HAZ } \\
\hline Stunting & 41 & 43 & 46 \\
\hline Moderate Stunting & 29 & 38 & 40 \\
\hline Severe Stunting & 12 & 5 & 6 \\
\hline Normal & 59 & 57 & 54 \\
\hline \multicolumn{4}{|l|}{ WAZ } \\
\hline Underweight & 18 & 15 & 10 \\
\hline Moderate Underweight & 11 & 12 & 8 \\
\hline Severe Underweight & 7 & 3 & 2 \\
\hline Normal & 82 & 85 & 90 \\
\hline \multicolumn{4}{|l|}{ Disease } \\
\hline Present & 15 & 8 & 4 \\
\hline Absent & 85 & 92 & 96 \\
\hline \multicolumn{4}{|l|}{ Vitamin-A Intake } \\
\hline Taken & 36 & 43 & 62 \\
\hline Not Taken & 64 & 57 & 38 \\
\hline \multicolumn{4}{|l|}{ Handwashing } \\
\hline Done & 47 & 58 & 75 \\
\hline Not Done & 53 & 42 & 25 \\
\hline \multicolumn{4}{|l|}{ Food Groups Taken } \\
\hline$<4$ food groups & 65 & 49 & 42 \\
\hline $4 / 4+$ food groups & 35 & 51 & 58 \\
\hline
\end{tabular}

The Table 2 exhibits food groups, disease and worm infestation among the three studies were statistically significant $(\mathrm{p}<.05)$. Simultaneously, hand washing, vitamin A intake and worm infestation was associated with disease condition $(\mathrm{p}<.05)$. Moreover, hand washing, vitamin A intake among the three study areas showed significant result. 
Table 2. Comparison of their mean along with the different subjects to test the significant level to show the effect of nutritional status on under-five children

\begin{tabular}{|c|c|c|}
\hline Variables & Mean \pm Std. deviation & p-value \\
\hline \multicolumn{3}{|c|}{ Food groups over study area } \\
\hline Rohingya Camp & $1.38 \pm 0.48$ & \multirow{3}{*}{$.014^{a}$} \\
\hline Surrounding Area & $1.47 \pm 0.50$ & \\
\hline Dumki Area & $1.59 \pm 0.50$ & \\
\hline \multicolumn{3}{|l|}{ Disease over study area } \\
\hline Rohingya Camp & $1.36 \pm 0.48$ & \multirow{3}{*}{$.000^{a}$} \\
\hline Surrounding Area & $1.63 \pm 0.49$ & \\
\hline Dumki Area & $1.71 \pm 0.46$ & \\
\hline \multicolumn{3}{|c|}{ Worm infestation over study area } \\
\hline Rohingya Camp & $1.54 \pm 0.50$ & \multirow{3}{*}{$.048^{a}$} \\
\hline Surrounding Area & $1.67 \pm 0.47$ & \\
\hline Dumki Area & $1.70 \pm 0.46$ & \\
\hline \multicolumn{3}{|c|}{ Handwashing over disease } \\
\hline Present & $1.15 \pm 0.36$ & \multirow[t]{2}{*}{$.000^{b}$} \\
\hline Absent & $1.59 \pm 0.49$ & \\
\hline \multicolumn{3}{|c|}{ Vitamin-A intake over disease } \\
\hline Present & $1.15 \pm 0.36$ & \multirow[t]{2}{*}{$.000^{b}$} \\
\hline Absent & $1.80 \pm 0.39$ & \\
\hline \multicolumn{3}{|c|}{ Worm infestation over disease } \\
\hline Present & $1.26 \pm 0.44$ & \multirow[t]{2}{*}{$.000^{b}$} \\
\hline Absent & $1.92 \pm 0.27$ & \\
\hline \multicolumn{3}{|c|}{ Handwashing over study area } \\
\hline Rohingya Camp & $1.22 \pm 0.42$ & \multirow{3}{*}{$.000^{a}$} \\
\hline Surrounding Area & $1.57 \pm 0.50$ & \\
\hline Dumki Area & $1.39 \pm 0.50$ & \\
\hline \multicolumn{3}{|c|}{ Vitamin A intake over study area } \\
\hline Rohingya Camp & $1.29 \pm 0.46$ & \multirow{3}{*}{$.000^{a}$} \\
\hline Surrounding Area & $1.65 \pm 0.48$ & \\
\hline Dumki Area & $1.64 \pm 0.48$ & \\
\hline
\end{tabular}

\section{Note: ${ }^{a} \mathrm{P}$ value for One way ANOVA Test}

${ }^{\mathrm{b}} \mathrm{P}$ value for Independent t-test

Bolded Italic values indicate statistical significance $\mathrm{p}<0.05$

\section{DISCUSSION}

This study explored the wasting, stunting and underweight condition of Rohingya refugee children were $13 \%, 41 \%$ and $18 \%$. The study of Rohingya, Bangladesh and Kuala Lumpur revealed wasting, stunting and underweight were $16 \%, 3 \%, 14.6 \%$ and $16.1 \%, 11.5 \%, 27.5 \%$ respectively [17, 19]. This study found that the condition of the Refugees children were nutritionally unsatisfactory. The occurrence of this study was due to forceful displacement from their country and collapsing their income level, housing condition, sanitary condition as well as their food practice was also changed [2]. Moreover, in this study diseased children was $15 \%$ which was also high as compared to the host communities. A similar study of Fronti and March, (2002) and survey report of IC Net Limited, (2018) revealed that due to limited number of health centers that could rendered them with all facilities of health care and suggestion that they could follow to overcome the disease condition [20,21]. This study found hand washing practice was $47 \%$ and vitamin A intake $36 \%$ of the Rohingya refugee children compared to Bangladeshi children which was similar to the study of World Food Programme, (2017) showing vitamin A consumption was $26 \%$ and diseased (due to diarrhea) was $40.4 \%$ for living in the coastal areas along with the lack of supply of fresh water and the vitamin A intake was poor due to limited number of campaign by government and non-government organizations $[11,22]$. The food groups taken by the Rohingya children <4 were $65 \%$ which was very high in comparison with other areas of Bangladesh [23] because the amount of rations/reliefs that was given to them which was very difficult to distribute in the family and maximum they could afford only 2 food groups and they couldn't engage themselves to any types of jobs in host countries.

Our findings revealed food groups, disease, worm infestation and vitamin A intake over the study area were statistically significant $\mathrm{p}<.05$. The study of Haddad, (2011) and Freeman et al., denoted agricultural food had an effect on nutritional status and the disease, worm infestation over their study area were statistically significant $\mathrm{p}<.05[24,25]$. This study explored food groups intake by Rohingya Refugee underfive children were less ( $<4$ food groups) than the Bangladeshi child because they are getting rations/reliefs from the government, non-government agencies and foreign agencies which was restricted but the Bangladeshi children family were affording different types of foods as they were engaged to different types of jobs easily but the refugees couldn't [4, 26]. Moreover, the study of Sultana, 2011 showed the probability of disease over the Rohingya children were different in compared to Bangladesh due 
to the unhygienic, poor standard of living in the refugee camp and lack of awareness specially unconsciousness [5, 27, 28]. According to the study of UNICEF, (2018) worm infestation and vitamin A intake of Rohingya children was different from host countries which were similar to our study because of limited number of campaign in the refugee camp, lack of consciousness and negligence of the family [11, 26]. This study revealed hand washing, worm infestation and vitamin A consumption over disease condition were statistically significant which were similar to the study of UNICEF, (2018) showing inappropriate hand washing and lack of fresh water causes diseases as well as if the worm infestation was not done then all the nutrients in the body will be absorbed by the worms which will make us malnourished and vulnerable to disease. Vitamin A intake negligence would suffer the children with different kind of diseases due to vitamin A deficiency like liver disorders, fat mal-absorption, night blindness etc [11,29].

The study explored the comparison of the nutritional status of Rohingya Refugee under-five children and the other areas of Bangladeshi children (Surroundings of Cox's Bazar and Dumki, Patuakhali) found wasting and underweight condition of the Rohingya Refugee under-five children were much more than the Bangladeshi under-five children. Moreover, disease percentage, vitamin A consumption, worm infestation, hand washing practice and $4 / 4+$ food groups intake percentage were also inferior to Bangladeshi child. This study will be helpful for the health promotional authority and national policy maker to take intervention programs on nutritional status improvement of the under five children of Rohingya Refugees.

Based on the supplementary analysis we showed comparison between the 0-5 years Rohingya Refugee children and Bangladeshi Children (Surrounding area of Cox's Bazar and Dumki, Patuakhali) and also the effect of nutritional status on them which displayed Rohingya Refugee under-five children were suffering most than the Bangladeshi children. So, it was relatively evident that we should focus on the improvement of nutritional status of 0-5 years Rohingya Refugee Children. Therefore, it was utmost important to improve their status by proper hand washing, worm infestation by tablets, vitamin A consumption to fight night blindness, disease prevention and finally $4 / 4+$ food group intake daily. Therefore, the present study provides novel benchmark data for other future studies to replicate and extend by the intervention of vitamin A consumption, worm infestation, awareness building for disease prevention, proper hand washing practice and 4/4+ food groups intake daily which will ultimately improve the nutritional status of Rohingya Refugee under-five children.

The present study was not without its limitation. Firstly, the data we had collected was only 300 which was from three study areas, due to scarcity of time and resources we couldn't collect more data. Secondly, we had collected the Rohingya children data randomly and could not finish the whole area for the collection of 100 children, if we could finish it, then it could be more authentic than any other work in this field. Finally, all the data were self-report which was subjected to well-known method biases including such things as social desirability biases and memory recall biases. Since this study was based on a cross-sectional data and as a result we cannot establish causal association.

\section{CONCLUSION}

Nutritional profile of Rohingya refugee children were much more unsatisfactory in compared to our national nutritional profile. In the study population, there was high prevalence of malnutrition among Rohingya children, especially wasting and underweight compared to other areas of Bangladesh. Therefore it is very important to improve their nutritional status by proper hand washing, worm infestation by tablets, vitamin A consumption to fight night blindness, disease prevention and finally $4 / 4+$ food group intake daily by implementation of policy for 0-5 year's old Rohingya Refugee children to have a positive health impact. It will play an important role for having a healthy society of Rohingya Refugees.

\section{REFERENCES}

[1] United Nations High Commission for Refugees. UNHCR Global Trends: Forced Displacement in 2014. 2015.

[2] M. M. Islam and T. Nuzhath, "Health risks of Rohingya refugee population in Bangladesh : a call for global attention," Journal of global health, vol. 8, no. 2, pp. 8-11, 2018.

[3] E. K. Pdes, "States of denial A review of UNHCR's response to the protracted situation of stateless Rohingya refugees in Bangladesh," The UN Refugee Agency, December 2011.

[4] K. Parks, "Park s Textbook of Preventive and Social Medicine," $23^{\text {rd }}$ Edition, Bhanot, 2015.

[5] S. Islam, T. G. Mahanta, R. Sarma, and S. Hiranya, "Nutritional Status of under 5 Children belonging to Tribal Population Living in Riverine (Char) Areas of Dibrugarh District, Assam," Indian J Community Med., vol. 39, no. 3, pp. 9-10, 2014.

[6] A. Bhatia et al., "A rapid needs assessment among the Rohingya and host communities in Cox's Bazar, Bangladesh : a randomized survey," Ideas, pp. 1-21, 2018. 
[7] UNHCR, Situation refugee response in Bangladesh, 2019. (Online). Available: https://data2.unhcr.org/en/situations/myanmar_refugees

[8] Haroon, R., Uddin, M., Choudhury, A., \& Ferdous, Z., "Nutritional status of Rohingya under-5 children in Jamtoly Rohingya camp," African Journal of Biological Sciences, vol. 2, no. 3, pp. 113-116, 2020.

[9] Black, R. E., Victora, C. G., Walker, S. P., Bhutta, Z. A., Christian, P., De Onis, M., \& Uauy, R., "Maternal and child undernutrition and overweight in low-income and middle-income countries," The lancet, vol. 382, no. 9890, pp. 427-451. 2013.

[10] Jesmin, A., Yamamoto, S., Malik, A. and Haque M., "Prevalence and determinants of chronic malnutrition among preschool children: a cross-sectional study in Dhaka city, Bangladesh," Journal of Health, Population and Nutrition, vol. 29, no. 5, pp. 494-499, 2011.

[11] V. One, Evaluation of UNICEF's Response to the Rohingya Refugee Crisis in Bangladesh, November, 2018.

[12] M. A. Prodip, "Health and Educational Status of Rohingya Refugee Children in Bangladesh," Journal of Population and Social Studies [JPSS], vol. 25, no. 2, pp. 135-146, 2017.

[13] Maher Sattar, "Rohingya camps in Bangladesh and Thailand, worlds apart, Al Jazeera, 2017. [Online]. Available: https://www.aljazeera.com/blogs/asia/2017/01/rohingya-camps-bangladeshthailand-worlds-170127113046730.html

[14] Bennett J., Myanmar: Rohingya refugees face increasing hostility in southern Bangladesh. ABC News 2017. [Online]. Available: http://www.abc.net.au/news/2017-09-28/rohingya-refugees-face-increasing-hostility-inbangladesh/8995238

[15] Bangladesh to return 300 Rohingya a day. BBC News, 2018. [Online]. Available: http://www.bbc.com/news/worldasia-42699602

[16] M. Wijnroks et al., "Surveillance of the Health and Nutritional Status of Rohingya Refugees in Bangladesh," Disasters, vol. 17, no. 4, pp. 348- 356, 1993.

[17] Abdullah, A. B. U. A., Rifat, M. A., \& Hasan, T., "Infant and Young Child Feeding (IYCF) Practices, Household Food Security and Nutritional Status of Under-five Children in Cox's Bazar, Bangladesh," Current Research in Nutrition and Food Science, vol. 06, no. 3, pp. 789-797, 2018.

[18] Dawson-Hahn, E. E., Pak-Gorstein, S., Hoopes, A. J., \& Matheson, J., "Comparison of the nutritional status of overseas refugee children with low income children in Washington State," PLoS One, vol. 11, no. 1, pp. 1-13, 2016.

[19] Teng, T. S., \& Zalilah, M. S. "Nutritional Status of Rohingya Children in Kuala Lumpur," Malaysian Journal of Medicine and Health Sciences, vol. 7, no. 1, pp. 41-49, 2011.

[20] S. Fronti and H. March, "10 Years for Rohingya Refugees in Bangladesh: Past, Present and Future," Medicines Sans-Frontieres, pp. 1-45, 2002.

[21] W. W. Are and K. Indicators, "Initial Findings : Impact on the Host Communities Affected by the Rohingya Crisis IC Net Limited,” Ic Net Limited, vol. 796, pp. 1-10, 2018.

[22] World Food Programme, Rohingya Emergency Vulnerability Assessment (Reva)-Summary Report, 2017. [Online]. Available: https://reliefweb.int/sites/reliefweb.int/files/resources/WFP-0000050429.pdf.

[23] B. A. Islam, "Economic and Social Impact of the Rohingya Crisis," University of Liberal Arts Bangladesh, pp. 1-4, 2018.

[24] Haddad L., et al., "Systematic review A systematic review of agricultural interventions that aim to improve nutritional status of children," BMJ, vol. 344, pp. 1-7, May 2011.

[25] Freeman, M. C., Garn, J. V, Sclar, G. D., Boisson, S., Medlicott, K., Alexander, K. T., Clasen, T. F., "The impact of sanitation on infectious disease and nutritional status : A systematic review and meta-analysis," International Journal of Hygiene and Environmental Health, vol. 220, no. 6, pp. 928-949. 2017.

[26] S. Report, "Health Survey in Kutupalong and Balukhali Refugee Settlements, Cox's Bazar, Bangladesh," Medecins Sans Frontieres, pp. 1-50, December, 2017.

[27] N. Sultana, "Health care at Rohingya Refugee Camp A case study on RTM Initiative," Acces Helath Internationa, pp. 1-15, July 2011.

[28] Islam K., et al., "Nutritional Status of Under-5 Children of Forcibly Migrated People Living in Ukhia, Cox Bazar, Bangladesh," J Nutr Health Sci., vol. 5, no. 4, p. 409, 2018

[29] R. Crisis, "Rohingya Crisis in Cox's Bazar, Bangladesh," Health Sector Bulletin, no. 4, pp. 1-17, 2018. 